\title{
A comparative study of osteopontin expression, Ki67 index and prognosis in squamous cell carcinoma and cysts of the oral cavity
}

\author{
Marta Woźniak ${ }^{1}$, Marek Nahajowski ${ }^{2}$,Sylwia Hnitecka ${ }^{3}$, Monika Rutkowska ${ }^{4}$, Grzegorz Marek ${ }^{5}$, \\ Anil Agrawal ${ }^{5}$, Sebastian Makuch $^{1}$, Siddarth Agrawal ${ }^{1}$, Piotr Ziółkowski ${ }^{1}$ \\ ${ }^{1}$ Department of Pathology, ${ }^{2}$ Department of Maxillofacial Orthopaedics and Orthodontics, ${ }^{3}$ Oral Surgery Department, ${ }^{4}$ Department of Maxillo-Facial \\ Surgery, ${ }^{5}$ Second Department and Clinic of General and Oncological Surgery, Wroclaw Medical University, Wrocław, Poland \\ Contributions: (I) Conception and design: M Woźniak, P Ziółkowski, S Agrawal; (II) Administrative support: M Woźniak, M Rutkowska, A Agrawal; (III) \\ Provision of study materials or patients: M Nahajowski, S Hnitecka; (IV) Collection and assembly of data: M Nahajowski, S Hnitecka, S Makuch; (V) \\ Data analysis and interpretation: G Marek, S Agrawal; (VI) Manuscript writing: All authors; (VII) Final approval of manuscript: All authors. \\ Correspondence to: Marta Woźniak, MD, PhD. Department of Pathology, Wroclaw Medical University, ul. K. Marcinkowskiego 1, 50-368 Wrocław, \\ Poland. Email: Marta.wozniak@umed.wroc.pl.
}

\begin{abstract}
Background: Recent studies have shown a strong relationship between the expression of osteopontin and oral carcinogenesis. Osteopontin $(\mathrm{OPN})$ has been shown to play a major role in regulating the aggressiveness of cancer cells and promote tumor growth. Odontogenic cysts are an essential aspect of oral and maxillofacial pathology. They are relatively frequent lesions with different clinical behavior. Some of them may have a proliferative pattern of growth and neoplastic nature. Evaluation of osteopontin expression with Ki-67 index may help examine clinical behavior and recurrence of oral squamous cell cancer and radicular cyst patients.

Methods: A total of 44 oral cavity cancer cases and 21 cysts samples were analyzed by immunohistochemical staining. Data used for analysis were derived from medical records. The following information was obtained from all patients' medical records: survival, age, sex, lymph node status, tumor size, and location, as well as grade and histologic type of tumor. Expression status of OPN and Ki-67 was statistically assessed.

Results: Our data demonstrated that for summary immunoreactive scores of OPN and Ki-67 expressions in OSCC vs. RC patients statistical significance was found for both markers' between OSCC and RC groups. Moreover, osteopontin is significantly higher expressed in larger OSCC tumors.

Conclusions: In conclusion, the role of OPN expression both in oral squamous cancer cells and radicular cyst and possible correlation with demographic and clinicopathological features remain undetermined in some aspects, further high-powered studies to develop a more standardized assessment of Ki-67 and osteopontin expression in OSCC and are needed.
\end{abstract}

Keywords: Oral squamous cell carcinoma (OSCC); oral cyst; osteopontin; Ki-67; immunohistochemistry

Submitted Jul 16, 2019. Accepted for publication Oct 12, 2019.

doi: $10.21037 /$ tcr.2019.12.08

View this article at: http://dx.doi.org/10.21037/tcr.2019.12.08

\section{Introduction}

The incidence of head and neck cancer is increasing, being known as the third most frequent cause of death in developing countries $(1,2)$. Head and neck squamous cell carcinoma is the fifth most common malignant tumor that arises in various anatomical locations, including oral cavity, oropharynx, larynx, and hypopharynx. Oral squamous cell carcinoma (OSCC) accounts for a significant proportion, with approximately 300,000 new cases annually worldwide (3). Despite modern therapy, the 5 -year survival rate for this cancer has not improved over the last decades, being $80 \%$ for early detected lesions, although for advanced tumors this number is reduced to almost $30-50 \%(4,5)$.

Proliferative index activity in OSCC determines the rate of its growth and aggressiveness, which affects the choice of treatment and outcome (6). The fraction of dividing tumor 
cells can be assessed using proliferation markers, such as $\mathrm{Ki}-67$ antigen. Expression of the Ki-67 antigen is observed in each phase of the cell cycle (G1, S, G2, and M), except for the G0 phase (7). It quickly degrades after mitosis, and a half-life of detectable antigen is one hour or less. The presence of overexpression of this protein indicates cell proliferation, is considered a gold standard in determining the cancer cell proliferation index. In precancerous lesions, it was found that the expression of this factor increases with the severity of the dysplasia $(8,9)$. Recently it was confirmed to be an effective aid to grade the OSCC tumors (10).

One of the markers that have recently been linked to the development, progression, and metastasis in many types of human tumors is osteopontin (OPN). It is a calcium-binding glycophosphoprotein, belonging to the SIBLING family (small integrin-binding ligand and $\mathrm{N}$-linked glycoprotein), present in many normal tissues (11). OPN is essential for physiological processes like wound healing, bone resorption, tissue remodeling, immune reactions, or vascularization. However, several reports reveal that osteopontin is expressed in tumor-shaped stromal cells and leads to cancer progression (12-14). Recent studies show that OPN is overexpressed in tumor tissues and serum samples from patients with various cancers (13). It has been shown to have a prognostic significance in patients with head and neck cancer previously treated with radiotherapy (14). OPN is associated with tumor hypoxia and malignant phenotype (15). Therefore, it is considered to be a tumorassociated protein that promotes tumor development and metastasis (16).

Studies from recent years have shown a strong relationship between the expression of osteopontin and oral carcinogenesis. Devoll et al. have reported that almost $67 \%$ of oral squamous cell carcinomas, and almost $54 \%$ of all oral carcinomas in situ lesions are immunoreactive for osteopontin (17). Moreover, tumors of the tongue that overexpress osteopontin tend to be more aggressive and have a worse prognosis (18). OPN expression has already been studied in OSCC, emphasizing its role as an indicator for tumor progression and potential risk of metastasis (17,19-22).

Odontogenic cysts are an essential aspect of oral and maxillofacial pathology. They are relatively frequent lesions with different clinical behavior. Some of them may have a proliferative pattern of growth and neoplastic nature, which is why they have been subject of many studies (23-29). Expression of OPN in odontogenic cysts has not been well investigated (30).
In the present study, the expression of OPN and Ki-67 was evaluated in OSCCs (oral squamous cell carcinoma) and RCs (radicular cysts, being the inflammatory lesions), to examine their clinical behavior and recurrence. Another purpose was to investigate the correlation between these two markers and demonstrate their potential prognostic role in these lesions.

\section{Methods}

Patients with oral cavity cancer treated surgically at Maxillofacial Surgery Ward, 4th Military Hospital, Wroclaw, Poland from April 2015 to December 2017 were enrolled in the study. A total of 44 oral cavity cancer cases and 21 cysts samples were analyzed. Data used for analysis were derived from medical records. The following information was obtained from all patients' medical records: age, sex, lymph node status, tumor size, and location, as well as grade and histologic type of tumor. All patients underwent radical surgery and adjuvant therapy based on the recommendations of the Polish Union of Oncology.

\section{Immunobistochemistry}

The collected tissue samples were fixed with $10 \%$ neutralbuffered formalin for 24 hours, then processed and embedded in paraffin. The specimens were cut into $5 \mu \mathrm{m}$ sections and stained with hematoxylin-eosin (HE) to visualize morphological characteristics. The proper parts of the FFPE specimens for further immunochemical analysis were examined by pathologists and marked to extract cores for the tissue microarrays. The paraffin microarray blocks were prepared according to Arraymold Kit manufacture's instruction (IHC World, Maryland, USA), then cut into $5 \mu \mathrm{m}$ sections and heated in $60^{\circ} \mathrm{C}$ overnight. The next day the slides were deparaffinized, rehydrated, and stained using LSAB + Method (LSAB+ System HRP from Dako, Denmark). Slides were kept in Antigen Retrieval Solution ( $\mathrm{pH}$ 6.0) for 10 minutes. After cooling and washing in distilled water, endogenous enzymes were blocked by Peroxidase Blocking Reagent for 10 minutes. After washing in distilled water, the specimens were incubated with Protein Block Reagent for 15 minutes. The primary antibodies (anti-Ki-67, anti-OPN, Sigma Aldrich, Germany) diluted 1:100 in IHC Dilution Buffer were incubated overnight at $4{ }^{\circ} \mathrm{C}$. To obtain negative controls, the primary antibody was omitted in the procedure. The next day, slides were washed with PBS and incubated with anti- 
Table 1 Number (percentage) of OSCC patients in OPN expression for intensity, percentage positivity and summary score groups with respect to survival $(\mathrm{P}>0.05)$ and age $\geq 65$ and $<65$ years $(\mathrm{P}>0.05)$

\begin{tabular}{|c|c|c|c|c|c|c|c|c|c|c|c|}
\hline \multirow{3}{*}{ OPN } & \multirow{3}{*}{$\begin{array}{l}\text { Staining } \\
\text { score }\end{array}$} & \multicolumn{5}{|c|}{ Survival } & \multicolumn{5}{|c|}{ Age } \\
\hline & & \multicolumn{2}{|c|}{ Alive (N=27) } & \multicolumn{2}{|c|}{ Dead $(N=16)$} & \multirow{2}{*}{$P$ value } & \multicolumn{2}{|c|}{$<65(\mathrm{~N}=27)$} & \multicolumn{2}{|c|}{$\geq 65(\mathrm{~N}=17)$} & \multirow{2}{*}{$P$ value } \\
\hline & & $n$ & $\%$ & $\mathrm{n}$ & $\%$ & & $\mathrm{n}$ & $\%$ & $n$ & $\%$ & \\
\hline \multirow[t]{3}{*}{ Intensity score } & 0 & 7 & 25.9 & 3 & 18.8 & 0.581 & 6 & 22.2 & 4 & 23.5 & 0.272 \\
\hline & 1 & 10 & 37.0 & 5 & 31.3 & & 10 & 37.0 & 5 & 29.4 & \\
\hline & 3 & 5 & 18.5 & 2 & 12.5 & & 6 & 22.2 & 1 & 5.9 & \\
\hline \multirow{3}{*}{$\begin{array}{l}\text { Percentage } \\
\text { positivity score }\end{array}$} & 0 & 7 & 25.9 & 3 & 18.8 & 0.178 & 6 & 22.2 & 4 & 23.5 & 0.419 \\
\hline & 1 & 11 & 40.7 & 6 & 37.5 & & 10 & 37.0 & 8 & 47.1 & \\
\hline & 2 & 5 & 18.5 & 7 & 43.8 & & 7 & 25.9 & 5 & 29.4 & \\
\hline \multirow{5}{*}{ Summary } & 1 & 10 & 37.0 & 4 & 25.0 & & 9 & 33.3 & 5 & 29.4 & \\
\hline & 2 & 1 & 3.7 & 3 & 18.8 & & 2 & 7.4 & 3 & 17.6 & \\
\hline & 4 & 4 & 14.8 & 4 & 25.0 & & 4 & 14.8 & 4 & 23.5 & \\
\hline & 6 & 1 & 3.7 & 2 & 12.5 & & 6 & 22.2 & 1 & 5.9 & \\
\hline & 9 & 4 & 14.8 & 0 & 0.0 & & - & - & - & - & \\
\hline
\end{tabular}

OSCC, oral squamous cell carcinoma; OPN, osteopontin.

rabbit HRP-secondary antibody for 30 minutes in RT. The detection of the antibody/antigen reaction was visualized by DAB substrate in Chromogen Solution. Finally, samples were counterstained with hematoxylin, dehydrated afterward through alcohols and mounted in Faramount Aqueous Medium.

$\mathrm{Ki}-67$ and OPN staining were scored in the range $0-6$, according to the sum of the staining intensity (absent $=0$, low $=1$, moderate $=2$ and strong $=3$ ) plus the percentage of positively stained cells $(<5 \%=0 ; 6-25 \%=1 ; 26-50 \%=2$, $>51=3)$. Histological evaluation was performed by the two independent pathologists and the pictures were taken by the light microscopy at the magnification 100x and 200x using Nikon Eclipse 80i with camera DS-Fil-U2 (Amsterdam, The Netherlands).

\section{Statistical analysis}

The statistical analysis was performed using the Statistica v. 12 software (StatSoft, Inc., Tulsa, OK, USA). The comparison of the values was carried out by the MannWhitney $\mathrm{U}$ test, $\mathrm{P}$ values $<0.05$ were considered as statistically significant. The concordance between the two immunohistochemical examinations was estimated by calculating the overall percentage of agreement (concordance) and the $\kappa$ coefficient. The $95 \%$ confidence interval (CI) was estimated for $\kappa$. A $\kappa$ coefficient of more than 0.80 will correspond to an almost perfect agreement as per the scale proposed by Landis and Koch. The results of the analysis of patient survival as a probability of survival after a specified period of time are presented as KaplanMeier curves. For comparison of survival in two groups, a log-rank test was used.

\section{Results}

We have not observed statistically significant differences between OPN expression and patient survival, as shown in Table $1(\mathrm{P}>0.05)$. There was also no difference between the $\mathrm{Ki}-67$ proliferative index and survival, as depicted in Table 2 $(\mathrm{P}>0.05)$.

Study group demographic characteristics were analyzed concerning age and sex. The relation of both analyzed markers and age were assessed in patient groups equal 
Table 2 Number (percentage) of OSCC patients in Ki-67 proliferation index groups with respect to survival $(\mathrm{P}>0.05)$ and age $\geq 65$ and $<65$ years $(\mathrm{P}>0.05)$

\begin{tabular}{|c|c|c|c|c|c|c|c|c|c|c|c|}
\hline \multirow{2}{*}{$\mathrm{Ki}-67$} & \multirow{2}{*}{$\begin{array}{l}\text { Staining } \\
\text { score }\end{array}$} & \multicolumn{5}{|c|}{ Survival } & \multicolumn{5}{|c|}{ Age } \\
\hline & & $n$ & $\%$ & $n$ & $\%$ & $P$ value & $\mathrm{n}$ & $\%$ & $\mathrm{n}$ & $\%$ & $P$ value \\
\hline \multirow[t]{2}{*}{ Summary } & 1 & 17 & 60.7 & 11 & 61.1 & 0.998 & 20 & 64.5 & 9 & 52.9 & 0.087 \\
\hline & 2 & 8 & 28.6 & 5 & 27.8 & & 10 & 32.3 & 4 & 23.5 & \\
\hline
\end{tabular}

OSCC, oral squamous cell carcinoma.

Table 3 Number (percentage) of OSCC patients in Ki-67 proliferation index group and OPN expression for intensity, percentage positivity, and summary score for men and women $(\mathrm{P}>0.05)$

\begin{tabular}{|c|c|c|c|c|c|c|}
\hline \multirow{2}{*}{$\begin{array}{l}\text { Expression } \\
\text { pattern }\end{array}$} & \multirow{2}{*}{$\begin{array}{l}\text { Staining } \\
\text { score }\end{array}$} & \multicolumn{2}{|c|}{ Women } & \multicolumn{2}{|c|}{ Men } & \multirow{2}{*}{$P$ value } \\
\hline & & $\mathrm{n}$ & $\%$ & $\mathrm{n}$ & $\%$ & \\
\hline OPN (N) & & 17 & & 27 & & \\
\hline \multirow{4}{*}{$\begin{array}{l}\text { Intensity } \\
\text { score }\end{array}$} & 0 & 2 & 11.8 & 8 & 29.6 & \multirow[t]{4}{*}{0.347} \\
\hline & 1 & 5 & 29.4 & 10 & 37.0 & \\
\hline & 2 & 6 & 35.3 & 6 & 22.2 & \\
\hline & 3 & 4 & 23.5 & 3 & 11.1 & \\
\hline \multirow{4}{*}{$\begin{array}{l}\text { Percentage } \\
\text { positivity } \\
\text { score }\end{array}$} & 0 & 2 & 11.8 & 8 & 29.6 & \multirow[t]{4}{*}{0.291} \\
\hline & 1 & 7 & 41.2 & 11 & 40.7 & \\
\hline & 2 & 7 & 41.2 & 5 & 18.5 & \\
\hline & 3 & 1 & 5.9 & 3 & 11.1 & \\
\hline \multirow[t]{5}{*}{ Summary } & 0 & 2 & 11.8 & 8 & 29.6 & \multirow[t]{5}{*}{0.563} \\
\hline & 1 & 5 & 29.4 & 9 & 33.3 & \\
\hline & 2 & 2 & 11.8 & 3 & 11.1 & \\
\hline & 4 & 4 & 23.5 & 4 & 14.8 & \\
\hline & 6 & 4 & 23.5 & 3 & 11.1 & \\
\hline $\mathrm{Ki}-67(\mathrm{~N})$ & & 19 & & 29 & & \\
\hline \multirow[t]{3}{*}{ Summary } & 1 & 12 & 63.2 & 17 & 58.6 & \multirow[t]{3}{*}{0.445} \\
\hline & 2 & 4 & 21.0 & 10 & 34.5 & \\
\hline & 3 & 3 & 15.8 & 2 & 6.9 & \\
\hline
\end{tabular}

OSCC, oral squamous cell carcinoma; OPN, osteopontin.

and above 65 years of age and younger. There was no statistical difference in the age groups in OSCC patients for both OPN expression and Ki-67 proliferation index $(\mathrm{P}>0.05$; Tables 1,2); however, a trend of fewer high Ki-67 proliferation index cases was observed in patients younger than 65 ( $\mathrm{P}=0.087$, Table 2). There were also no significant correlations between men and women groups in the expression of the tested proteins, as shown in Table 3 for OPN and Ki-67, respectively $(\mathrm{P}>0.05)$.

The clinicopathological parameters taken into considerations were tumor size $(\mathrm{T})$ and the lymph node status $(\mathrm{N})$ and cell differentiation $(\mathrm{G})$. In OSCC patient groups, we found statistical significance in the relation of higher OPN expression in larger tumors $(\mathrm{T})$, as shown in Table 4. The significant correlation pertained to the intensity score $(\mathrm{P}=0.032)$ and the combined score of intensity and percentage positivity of stained cells $(\mathrm{P}=0.024)$, and though it was not observable for the percentage positivity alone score $(\mathrm{P}>0.05)$, the combined score significance emphasizes its relevance. The $\mathrm{Ki}-67$ proliferation index showed no statistical differences between tumor size groups, which were presented in Table $4(\mathrm{P}>0.05)$.

The comparison of nodal status (N), OPN intensity, percentage positivity score, and the summary score were showed in Table 5 and showed no significant correlation $(\mathrm{P}>0.05)$. The proliferative index of Ki-67 comparison with the nodal status is presented in Table 5. There were no statistically significant differences between these groups $(\mathrm{P}>0.05)$.

The expression of both analyzed markers showed no statistical differences concerning tumor differentiation $(G)$. The OPN expression in all scores showed no significance $(\mathrm{P}>0.05)$, and $\mathrm{Ki}-67$ proliferation index remained in no significant relation to the $\mathrm{G}$ trait (Table $6, \mathrm{P}>0.05$ ).

The mutual relation between the two analyzed proteins was also assessed. We found no significant relationship between the OPN summary score and Ki-67 proliferative index in the OSCC patient group ( $\mathrm{P}>0.05$, Table 7).

The control group of non-malignant lesions for our study were radicular cysts (RC). The OPN expression 
Table 4 Number (percentage) of OSCC patients for Ki-67 proliferation index groups and OPN expression intensity, percentage positivity, and summary score with respect to tumor size $(\mathrm{T})(\mathrm{P}=0.032$ for intensity score; $\mathrm{P}=0.024$ for summary; $\mathrm{P}>0.05$ for percentage positivity)

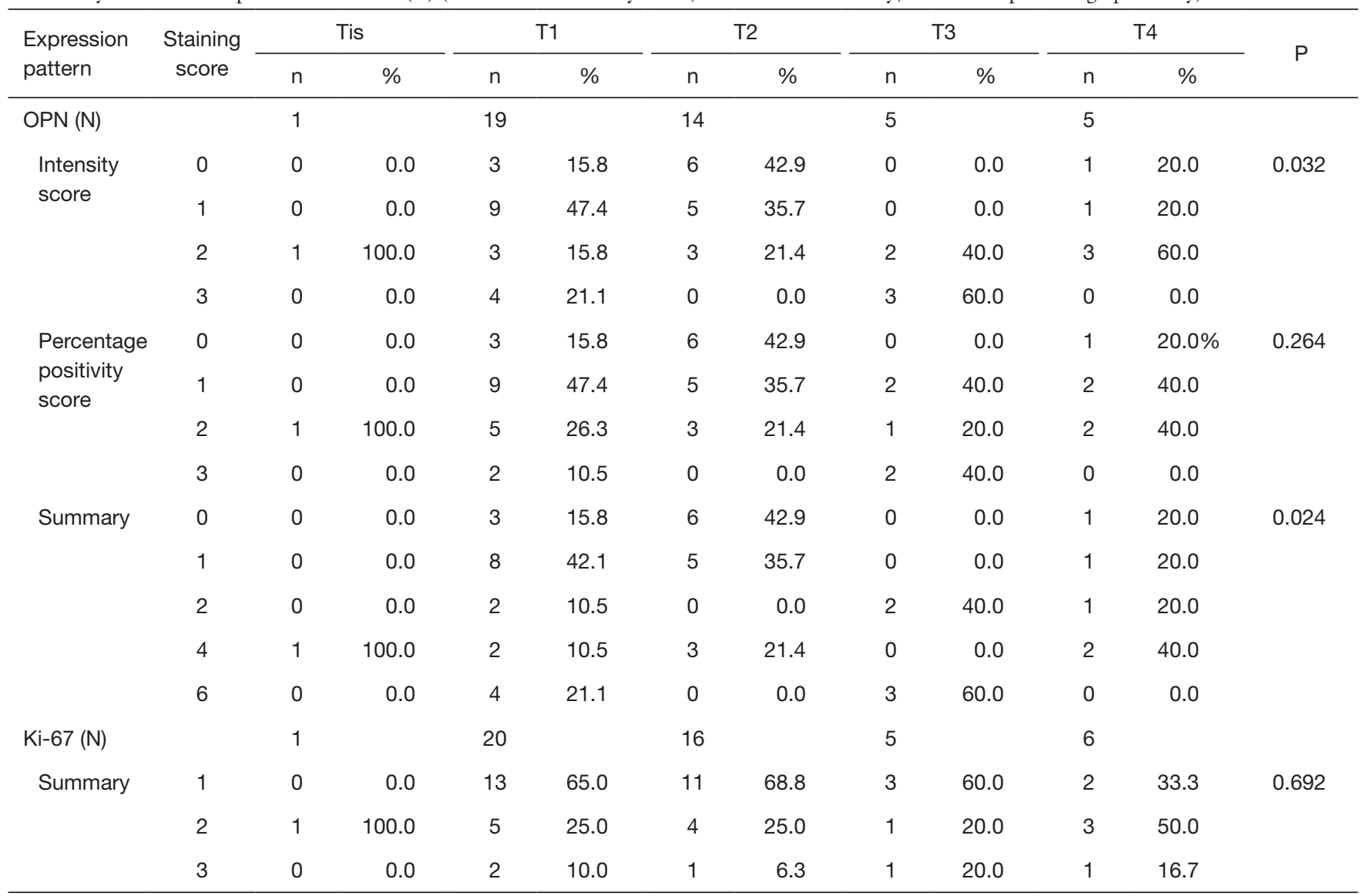

OSCC, oral squamous cell carcinoma; OPN, osteopontin.

intensity, percentage positivity, and summary scores did not differ significantly in RC study population in men and women, as shown in Table $8(\mathrm{P}>0.05)$.

The expression of OPN in the OSCC and RC groups were compared, and the analysis showed no significant differences in the intensity, percentage positivity, and combined scores $(\mathrm{P}>0.05$; Table 8$)$. A trend of fewer lowintensity scores in the RC group was observed $(\mathrm{P}=0.073$; Table 8); however, also no statistically significant differences were noted when summary score of low (0 or 1$)$ and high (2 or more) groups was assessed ( $\mathrm{P}>0.05$; $\mathrm{RR}=0.76$ for $95 \%$ $\mathrm{CI}$ ), as shown in Table 9. Our results support the hypothesis that high $(\geq 2)$ expression of OPN does not correlate with OSCC $v s$. RC differential diagnosis.

The Ki-67 proliferation index showed a statistically significant difference for the OSCC $v s$. RC diagnosis in the study group $(\mathrm{P}<0.001)$ as presented in Table 10. Similarly, the summary score of Ki-67 expression analysis of negative expression (0 or 1) and positive expression (2) yielded statistically significant difference between OSCC and RC patients $(\mathrm{P}=0.032)$ and $\mathrm{RR}(95 \% \mathrm{CI})$ for positive results equal to 0.08 (0.14 to 2.10 ) at 1.00 (ref.) for negative cases (Table 9). The data presented strongly suggest that the risk of cancer for negative cases is low. In patients with the positive test result, the relative risk of cancer is three and a half times higher than for the negative result $(\mathrm{RR}=3.53)$. Because $95 \%$ confidence interval (CI) does not contain 1, this risk is statistically significant. For the cut-off value of the Ki-67 summary score larger than one, the sensitivity is low and amounts only to $39.6 \%$ (Ki-67summary $>1$; SE $=39.6 \%)$, but specificity is very high $(\mathrm{SP}=100 \%)$, and area under curve for receiver operating characteristic (ROC AUC) analysis equals 0.698 (0.577 to 0.801$)$. Specificity, in this case, represents the probability that a patient with nonmalignant cyst will be classified as a healthy (non-cancer) patient (true negative) as a specific test yields a low number 
Table 5 Number (percentage) of OSCC patients for Ki-67 proliferation index groups and OPN expression intensity, percentage positivity, and summary score with respect to nodal status $(\mathrm{N})(\mathrm{P}>0.05)$

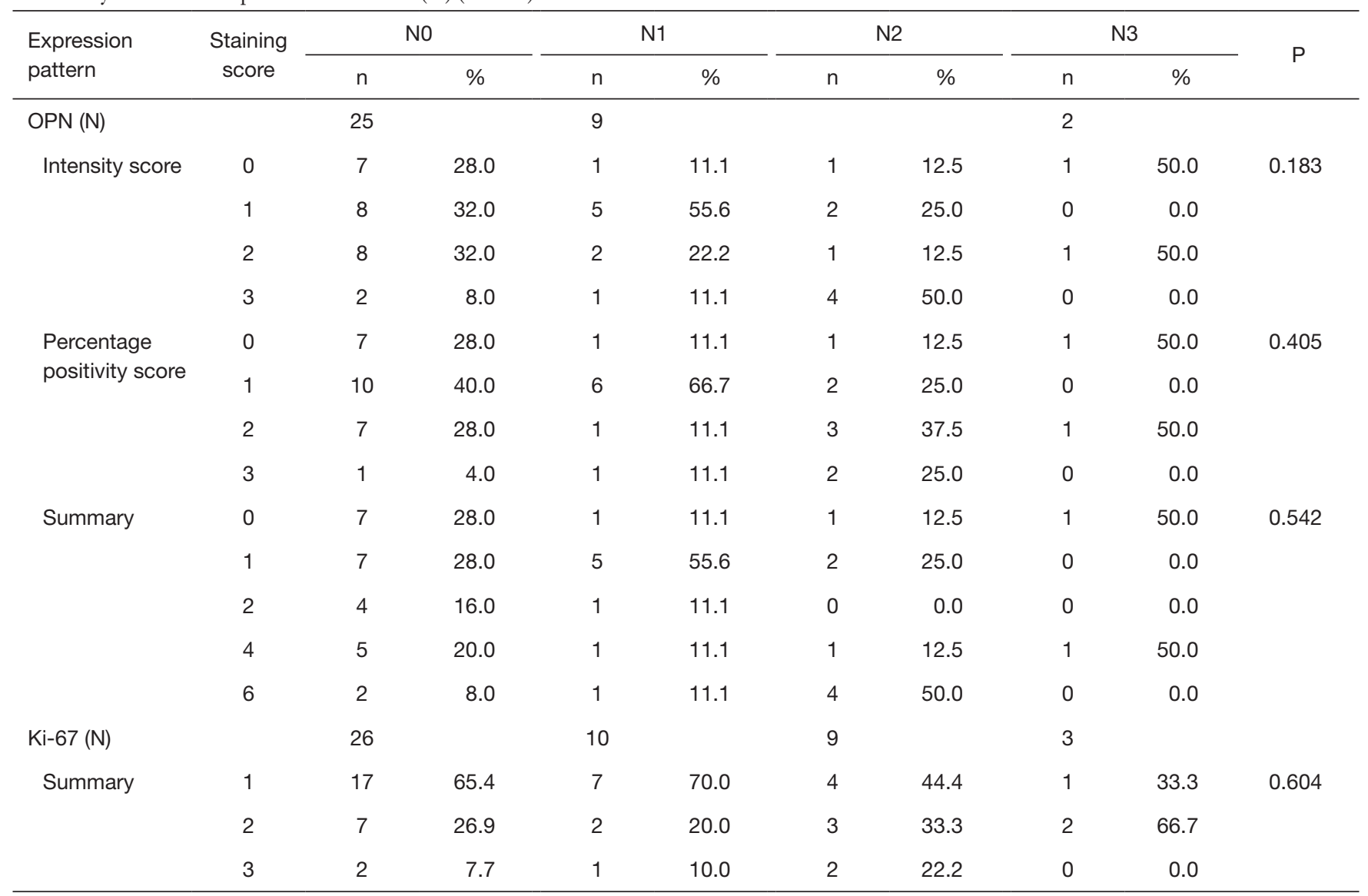

OSCC, oral squamous cell carcinoma; OPN, osteopontin.

of false positive results. The ROC analysis was presented in Figure $1 A$.

The U Mann-Whitney tests for summary scores of OPN and Ki-67 expressions in OSCC vs. RC patients were showed in Figure $1 B$ and $C$. Accordingly, to the above findings, statistical significance was found for both markers' summary score between OSCC and RC groups. Figure 2 presents representative images of immunohistochemical evaluation of osteopontin and $\mathrm{Ki}-67$ visualized with $\mathrm{DAB}$ substrate and haematoxylin for counterstaining.

\section{Discussion}

OSCC belongs to the ten most common cancers in the world. The mortality rate in OSCC remains high, thus seeking new agents of diagnosis and possible targeted therapy are of utmost importance $(1,2)$.

$\mathrm{OPN}$ is an acidic glycoprotein found in many tissues such as bones, macrophages, vascular smooth muscles, kidney, brain, epithelium cells. Its function varies in physiological and pathophysiological settings. Among many others, its most important functions include bone remodeling, immunostimulation, and proinflammatory activity, angiogenesis, but also inhibition of apoptosis, oncogenesis, and cancer progression. On the cellular level, OPN takes part in multiple signaling pathways which under malignant conditions induce cancer progression and its invasive properties $(17,18)$.

The expression of OPN in OSCC and RC in our study was assessed quantitatively by analyzing the intensity and percentage positivity of the stained cells. The reported expression amounted in the cumulative score to $45,5 \%$ of cases in OSCC and was not significantly different than the slightly higher expression in the benign control group being RC group (66.7\%) although a trend of weaker significance in intensity score between the two groups was found 
Table 6 Number (percentage) of OSCC patients for Ki-67 proliferative index scores and OPN expression intensity, percentage positivity, and summary score with respect to tumor differentiation $(\mathrm{G})(\mathrm{P}>0.05)$

\begin{tabular}{|c|c|c|c|c|c|c|c|c|}
\hline Expression pattern & Staining score- & \multicolumn{2}{|c|}{ G1 } & \multicolumn{2}{|c|}{ G2 } & \multicolumn{2}{|c|}{ G3 } & $P$ \\
\hline OPN (N) & & 18 & & 23 & & 2 & & \\
\hline \multirow[t]{3}{*}{ Intensity score } & 0 & 3 & 16.7 & 7 & 30.4 & 0 & 0.0 & 0.640 \\
\hline & 1 & 7 & 38.9 & 8 & 34.8 & 0 & 0.0 & \\
\hline & 3 & 3 & 16.7 & 3 & 13.0 & 1 & 50.0 & \\
\hline \multirow{3}{*}{$\begin{array}{l}\text { Percentage positivity } \\
\text { score }\end{array}$} & 0 & 3 & 16.7 & 7 & 30.4 & 0 & 0.0 & 0.231 \\
\hline & 1 & 7 & 38.9 & 11 & 47.8 & 0 & 0.0 & \\
\hline & 2 & 6 & 33.3 & 4 & 17.4 & 1 & 50.0 & \\
\hline \multirow{4}{*}{ Summary } & 1 & 6 & 33.3 & 8 & 34.8 & 0 & 0.0 & \\
\hline & 2 & 2 & 11.1 & 3 & 13.0 & 0 & 0.0 & \\
\hline & 4 & 4 & 22.2 & 2 & 8.7 & 1 & 50.0 & \\
\hline & 6 & 3 & 16.7 & 3 & 13.0 & 1 & 50.0 & \\
\hline $\mathrm{Ki}-67(\mathrm{~N})$ & & 19 & & 25 & & 3 & & \\
\hline \multirow[t]{3}{*}{ Summary } & 1 & 12 & 63.2 & 15 & 60.0 & 2 & 66.7 & 0.828 \\
\hline & 2 & 4 & 21.0 & 8 & 32.0 & 1 & 33.3 & \\
\hline & 3 & 3 & 15.8 & 2 & 8.0 & 0 & 0.0 & \\
\hline
\end{tabular}

OSCC, oral squamous cell carcinoma; OPN, osteopontin.

$(\mathrm{P}=0.073)$. Concurrent lack of significant differences in the OPN expression in OSCC $v s$. nonmalignant epithelial cells was reported by Devoll et al. and Routray et al. (17,31). Jiang et al. and Aravind et al. showed a statistically significant difference in OPN expression between OSCC cells and those of normal mucosa $(20,32)$. Matsuzaki et al. reported significantly higher staining of Ki-67 in OSCC compared to the normal epithelium and cell dysplasia, and a remarkable increase of staining at the invasion front of the tumor compared with non-invaded regions and Aravind et al. found significantly increasing OPN staining along with increasing severity of dysplasia $(19,32)$.

Our observation of no correlation between OPN expression and demographic features such as age and sex were consistent with the findings of the reviewed authors. However, Ingale et al. reported significantly higher expression of OPN in patients above 51 years of age (21).

No statistically significant differences in survival between expression subgroups in our study were supported by the data from Matsuzaki et al., however, Chien et al. found a significant impact of higher OPN expression on prognosis $(18,19)$.

Tumor differentiation groups did not correlate with the marker expression in our study population, which was consistent with the findings of Devoll et al. and Matsuzaki et al., however several authors including Aravind et al. and Lu et al. found a statistically significant increase of OPN expression with the loss of tumor differentiation $(17,19,22,32)$.

In our study, we found significantly higher OPN intensity staining score $(\mathrm{P}=0.032)$ and the combined staining and percentage positivity score $(\mathrm{P}=0.024)$ with the increasing tumor size $(\mathrm{T})$. Although the percentage positivity score did not follow this pattern of behavior, the results in the combined score category indicate overall increased OPN expression in larger OSCC tumors. Similarly, significantly higher OPN expression in larger tumors was observed by 
Table 7 Number (percentage) in OSCC patient groups of summary expression of OPN and Ki-67 proliferative index $(\mathrm{P}>0.05)$

\begin{tabular}{|c|c|c|c|c|c|c|c|}
\hline \multirow{2}{*}{ OPN-summary } & \multicolumn{6}{|c|}{ Ki-67 summary } & \multirow{2}{*}{$\mathrm{P}$} \\
\hline & $\mathrm{n}$ & $\%$ & $\mathrm{n}$ & $\%$ & $\mathrm{n}$ & $\%$ & \\
\hline 0 & 5 & 20.0 & 4 & 33.3 & 0 & 0.0 & 0.767 \\
\hline 1 & 7 & 28.0 & 3 & 25.0 & 3 & 60.0 & \\
\hline 4 & 5 & 20.0 & 2 & 16.7 & 1 & 20.0 & \\
\hline 6 & 5 & 20.0 & 2 & 16.7 & 0 & 0.0 & \\
\hline
\end{tabular}

OSCC, oral squamous cell carcinoma; OPN, osteopontin.

Table 8 Number (percentage) of RC patients OPN expression intensity, percentage positivity, and summary score with respect to sex groups, OSCC and RC groups $(\mathrm{P}>0.05)$

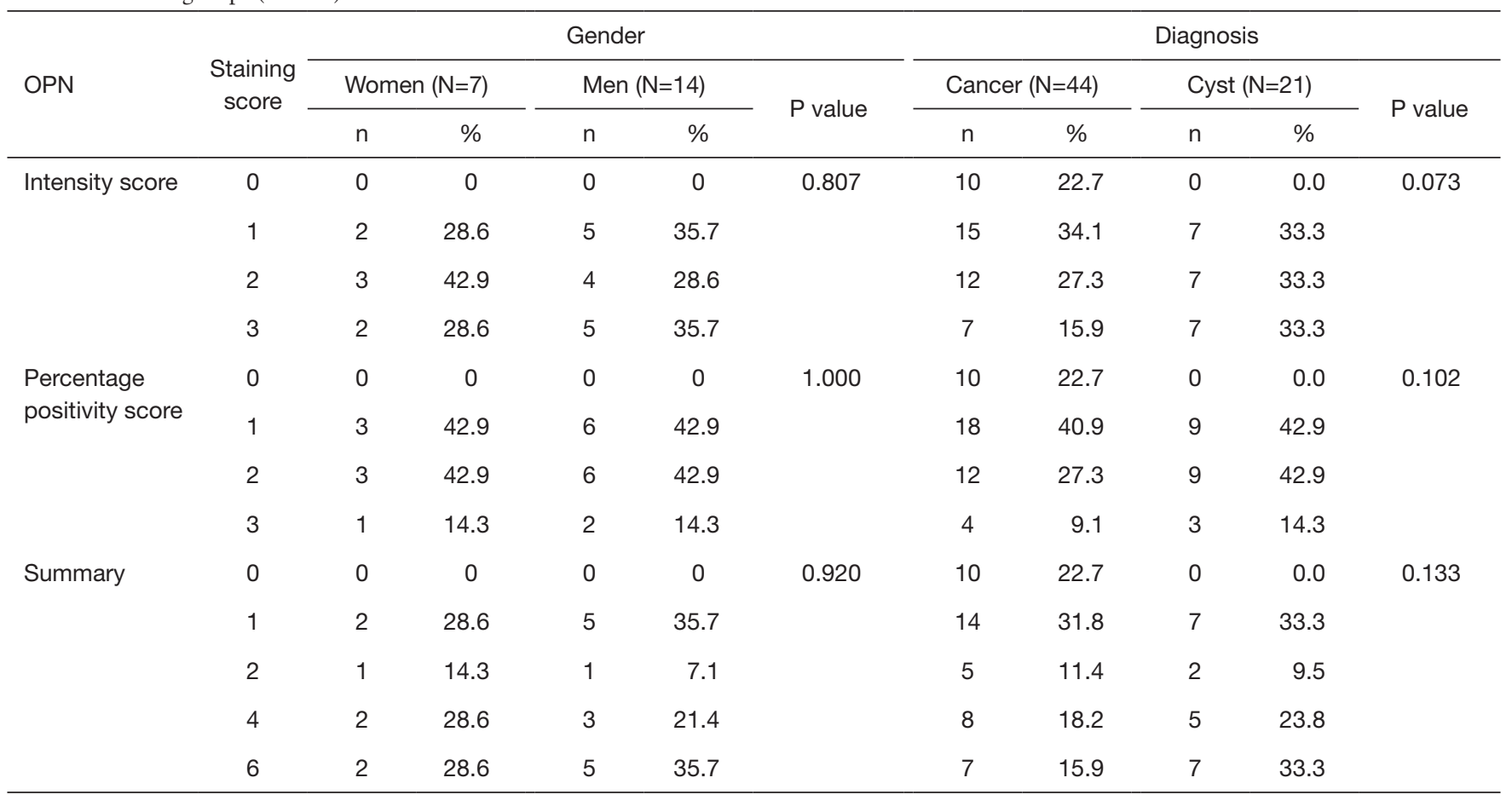

$\mathrm{RC}$, radicular cyst; OPN, osteopontin; OSCC, oral squamous cell carcinoma.

Chien et al., however, Matsuzaki et al. report no significant differences in this relation $(18,19)$.

Positive lymph node status was found in significant correlation with higher OPN expression by Chien et al. and Jiang et al., but Matsuzaki et al. found no such correlation which was consistent with our results (18-20).

Since there is scarce literature information about OPN expression in odontogenic keratocysts, our study included the subpopulation of radicular cysts (RC) as a control group.
RCs are prevalently inflammatory and degenerative lesions. Our results showed slightly higher expression of OPN in the RC group when compared to the OSCC patients but with no statistically significant correlation in both expression and sex analysis in the RC group. Although a trend in the higher sole OPN expression intensity score was observed in the RC group, such relation did not transfer for the summary score thus cannot be deemed conclusive. In our findings of the OPN expression in more than $66 \%$ 
Table 9 Number (percentage) of patients for Ki-67 proliferative index groups $(\mathrm{P}<0.001)$ and OPN expression summary score in OSCC and RC groups $(\mathrm{P}>0.05 ; \mathrm{RR}=0.68$ for $95 \% \mathrm{CI})$

\begin{tabular}{|c|c|c|c|c|c|c|}
\hline Marker & \multicolumn{2}{|c|}{ Cancer } & \multicolumn{2}{|c|}{ Cyst } & $P$ value & $\mathrm{RR}(95 \% \mathrm{Cl})$ \\
\hline \multicolumn{7}{|l|}{ OPN } \\
\hline Result of the test $(\mathrm{N})$ & 44 & & 21 & & & \\
\hline Negative $(0$ or 1$)$ & 24 & 54.5 & 7 & 33.3 & 0.182 & 1.00 (ref.) \\
\hline \multicolumn{7}{|l|}{ Ki-67 } \\
\hline Result of the test $(\mathrm{N})$ & 36 & & 21 & & & \\
\hline Negative $(0$ or 1$)$ & 29 & 80.60 & 21 & 100.00 & 0.032 & 1.00 (ref.) \\
\hline Positive (2) & 7 & 19.40 & 0 & 0.00 & & $0.08(0.14$ to 2.10$)$ \\
\hline
\end{tabular}

OPN, osteopontin; OSCC, oral squamous cell carcinoma; RC, radicular cyst.

Table 10 Number (percentage) of OSCC and RC patients in Ki-67 proliferative index groups $(\mathrm{P}<0.001)$

\begin{tabular}{|c|c|c|c|c|c|c|}
\hline \multirow{2}{*}{ Ki-67 } & \multirow{2}{*}{$\begin{array}{l}\text { Staining } \\
\text { score }\end{array}$} & \multicolumn{2}{|c|}{ Cancer $(\mathrm{N}=48)$} & \multicolumn{2}{|c|}{ Cyst (N=21) } & \multirow{2}{*}{$P$ value } \\
\hline & & $\mathrm{n}$ & $\%$ & $n$ & $\%$ & \\
\hline \multirow{3}{*}{$\begin{array}{l}\text { Summary } \\
\text { score }\end{array}$} & 1 & 29 & 60.4 & 21 & 100.0 & $<0.001$ \\
\hline & 2 & 14 & 29.2 & 0 & 0.0 & \\
\hline & 3 & 5 & 10.4 & 0 & 0.0 & \\
\hline
\end{tabular}

OSCC, oral squamous cell carcinoma; $\mathrm{RC}$, radicular cyst.

of RC cases is somewhat inconsistent with authors like Wang et al. and Salehinejad et al. who report absent or weak expression of this antibody, significantly lower than in subtypes of odontogenic cysts with proven higher neoplastic potential such as odontogenic keratocysts (OKCs) $(30,33)$. Although we know that OPN can be well expressed in non-malignant tissues due to its numerous physiological functions, these discrepancies require further investigation.

The complex role of OPN in both physiological and pathological processes, its multifaceted functions and complex upregulation in malignancies arising in cells of different origin pose a troublesome burden in the proper determination of its role. The studies on the subject are heterogenous concerning population size and ethnicity, choice of antibodies, cut-off points and methods of the protein expression assessment posing analytic challenge, which now calls for further studies on the subject with more standardized methodology.

Although Ki-67 as a nuclear protein proved to be an essential proliferation marker and a hallmark for numerous neoplasms, its expression in various cancers and its prognostic significance is far from homogenous across different tissue types (34-36).

It has been proven to be an excellent marker of neoplastic aggressiveness and prognostic significance in cancers originating in breast, lung, and prostate and already a standard in a diagnostic procedure often requiring more aggressive treatment $(35,36)$. Such simple correlation seems not to be the case for OSCC. Although analyzed over many years, the importance in disease assessment, correlation with clinicopathological parameters, and prognostic value is far from being soundly established.

There is little disagreement concerning the diagnostic value of Ki-67 expression and Ki-67 proliferative index PI in cancer cells, including OSCC. The reviewed authors such as Watanabe et al., Verma et al., Kurokawa et al. and Tumuluri et al. state significantly higher expression of Ki-67 in OSCC cells compared to health oral epithelium (8,37-39). Our study fully supports this thesis showing both Ki-67 proliferative index and summarized Ki-67 expression score to be significantly higher in OSCC than in non-cancerous oral epithelial tissues $(\mathrm{P}<0.001$ and $\mathrm{P}=0.032$ respectively). Moreover, the measured relative risk of OSCC was found to be three and a half times higher in $\mathrm{Ki}-67$ positive oral epithelial cells patients, with high specificity for true negatives, indicating that $\mathrm{Ki}-67$ could be a valuable marker of benign disease in $\mathrm{Ki}-67$ negative patients.

Much greater controversies pertain to the value of $\mathrm{Ki}-67$ expression as a prognostic tool in malignant diseases of oral 

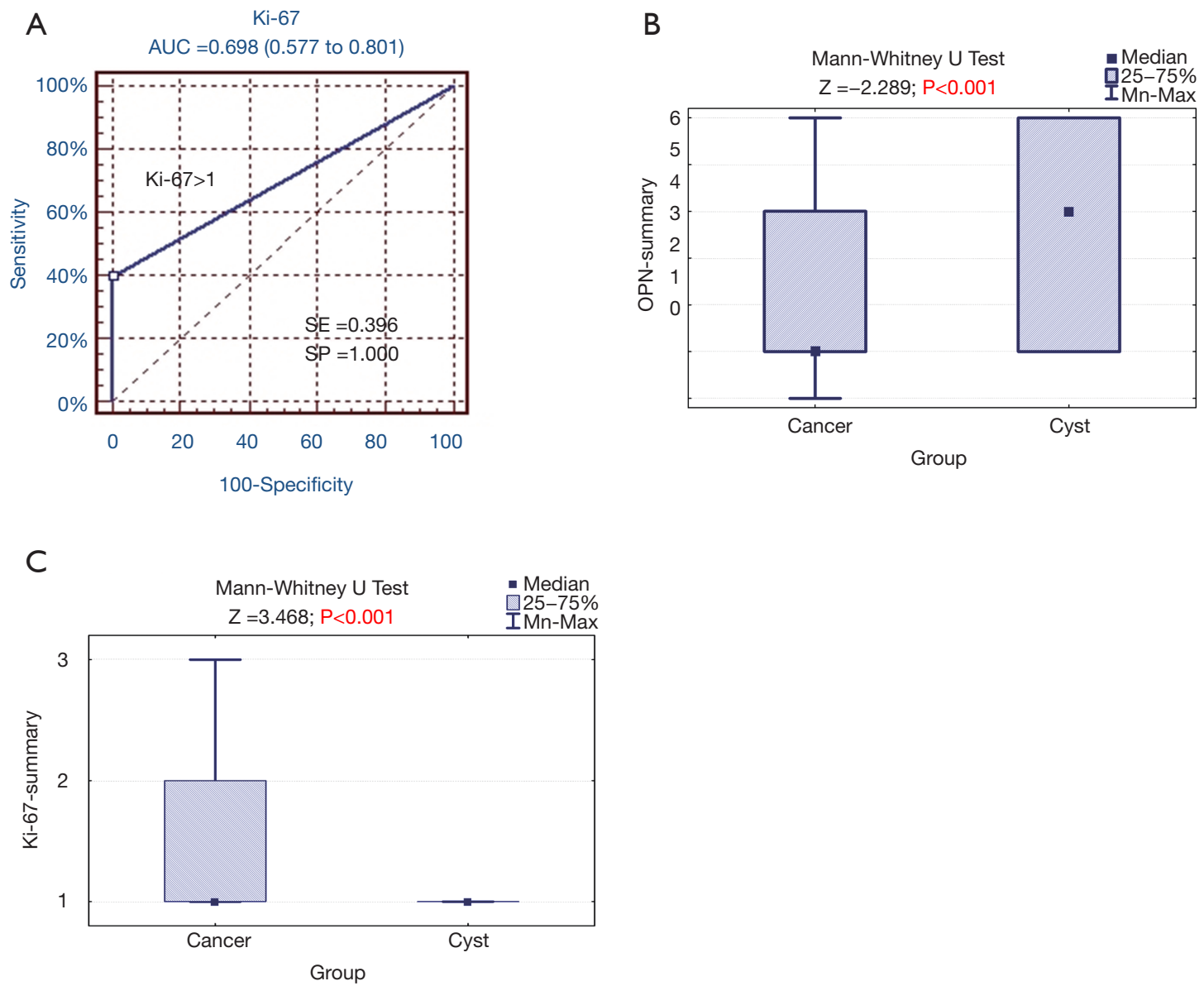

Figure 1 Statistical evaluation of ROC analysis and U Mann-Whitney test. (A) ROC (receiver operating characteristic) curve for summary expression of Ki-67; (B) the U Mann-Whitney test for OPN summary expression in OSCC and RC patients; (C) U Mann-Whitney test for Ki-67 summary expression in OSCC and RC patients. OSCC, oral squamous cell carcinoma; RC, radicular cyst; OPN, osteopontin.

epithelium. Its relation to survival in OSCC in multiple studies has shown contradicting results. Our results did not show statistically significant differences in survival in groups of various Ki-67 expression. Similar, not statistically significant relations were described by Lopes et al., Stoll et al., Gonzalez-Moles et al., Cortegoso et al., Watanabe et al. $(8,34,40-42)$. Contradictive findings of statistically significant correlation with survival and prognostic value of Ki-67 were reported by Klimowicz et al., da Silva et al., Myoung et al. (43-45). Freudelsperger et al. found Ki-67 to be a valuable predictive tool in stage I OSCC (6). Xie et al. in an extensive review of available in 2016 literature, narrowed from 801 to 30 papers for high validity of data, have concluded that $\mathrm{Ki}-67$ can be a negative prognostic marker in OSCC, especially in the Asian population (46). Their critical analysis of the studies shows yet many problems with a proper comparison of the study results, which were also noticed by the authors of this paper. The difference in sample sizes, the choice of antibodies used, cut off values, expression assessment methodology and heterogeneity of cancer tumors themselves in connection with the option of exact tissue sampling location as well as such demographical features as ethnicity might all amount to the observed discrepancies in the results.

Our results did not confirm significant differences in $\mathrm{Ki}-67$ expression when compared to the differentiation grade of the tumor $(\mathrm{G})$. Consistent results were reported by Lopes et al., Watanabe et al., Guimarães et al., however, there were also convincing reports from Bhuyan et al., Verma et al., Gonzalez-Moles et al., Dragomir et al., Motta et al. and Coutinho-Camillo et al. who found significantly higher Ki-67 expression in poorly differentiated tumors 

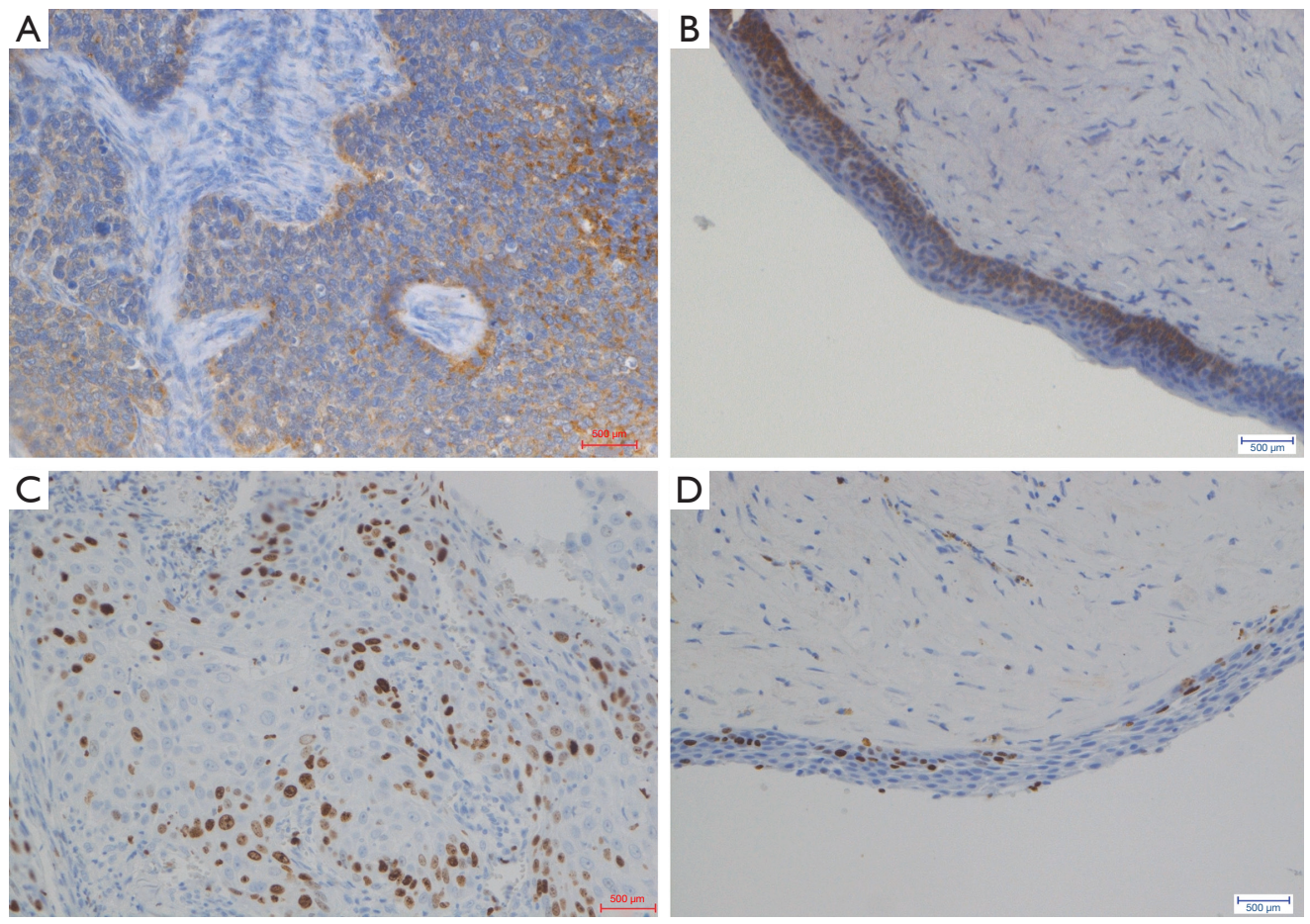

Figure 2 Representative images of immunohistochemical evaluation of osteopontin and Ki-67 visualized with DAB substrate and haematoxylin for counterstaining; 200× magnification. (A) Moderate immunoreactivity score cytoplasmic staining of osteopontin expression in oral cavity SCC carcinoma; (B) strong immunoreactivity score cytoplasmic staining of osteopontin expression in cyst located in the oral cavity; (C) moderate immunoreactivity score staining of nuclear Ki-67 in oral cavity SCC carcinoma; (D) low immunoreactivity score staining of nuclear Ki-67 expression in cyst located in the oral cavity. SCC, squamous cell carcinoma.

$(8,10,34,37,40,47-50)$.

No relation in tumor size $(\mathrm{T})$ and Ki-67 expression found in our study and supporting this observation data from Watanabe at al., Gonzalez-Moles et al., are in certain opposition to the findings of Lopes et al. and Guimarães et al. who found correlation between the examined protein expression and tumor size when adjusted for small $v s$. large tumors (T1-T2 vs. T3-T4) $(8,34,40,47)$.

Although most reviewed authors, Watanabe et al., Gonzalez-Moles et al., Lopes et al. Cortegoso et al. did not find statistically significant relation between Ki-67 expression and nodal status of the patients which was in concurrence with our results, some papers showed that the relation in this respect is significant $(8,10,34,40,42,47)$.

Before Ki-67 antigen can be widely used as a standardized tool to grade OSCC cases and possibly influence the therapeutic choices, future studies in more unified settings are needed.

\section{Limitation}

Limitations of our study may include small study populations and its retrospective character.

\section{Conclusions}

The Ki-67 expression could be a valuable tool in diagnostics of oral epithelial pathology, especially as a specific marker of true negative cases for malignancy. The prognostic value of $\mathrm{Ki}-67$ in OSCC and its relation to various demographic and clinicopathological parameters remain unclear both in our findings and in the literature review. Further high-powered studies to develop a more standardized assessment of Ki-67 expression in OSCC and are needed.

The role of OPN expression both in OSCC cells and $\mathrm{RC}$ and possible correlation with demographic and clinicopathological features remain undetermined. Although we found its significantly higher expression in larger OSCC 
tumors, due to many literature contradicting reports further studies in this field and standardization of IHC in OPN expression assessment in OSCC are required.

\section{Acknowledgments}

Funding: The publication was prepared under the project financed from the funds granted by the Ministry of Science and Higher Education in the "Regional Initiative of Excellence" program for the years 2019-2022, project number 016/RID/2018/19, the amount of funding 11998 121.30 PLN. The part of this work was supported by the Wroclaw Medical University grant no. ST.A010.16.018, ST.A010.17.006 and STM.A011.17.055.

\section{Footnote}

Conflicts of Interest: The authors have completed the ICMJE uniform disclosure form (available at http://dx.doi. org/10.21037/tcr.2019.12.08). The authors have no conflicts of interest to declare.

Ethics Statement: The authors are accountable for all aspects of the work in ensuring that questions related to the accuracy or integrity of any part of the work are appropriately investigated and resolved. The investigation was conducted in accordance with ethical standards, according to the Declaration of Helsinki (as revised in 2013), national and international guidelines. The archival FFPE blocks were used upon approval by the Local Ethics Committee. Data used for analysis were derived from medical records.

Open Access Statement: This is an Open Access article distributed in accordance with the Creative Commons Attribution-NonCommercial-NoDerivs 4.0 International License (CC BY-NC-ND 4.0), which permits the noncommercial replication and distribution of the article with the strict proviso that no changes or edits are made and the original work is properly cited (including links to both the formal publication through the relevant DOI and the license). See: https://creativecommons.org/licenses/by-ncnd $/ 4.0 \%$.

\section{References}

1. Forastiere A, Koch W, Trotti A, et al. Head and Neck Cancer. N Engl J Med 2001;345:1890-900.
2. Thun MJ, Linet MS, Cerhan JR, et al. Schottenfeld and Fraumeni cancer epidemiology and prevention. Fourth Edition. New York, NY, Oxford University Press, 2017.

3. Ferlay J, Soerjomataram I, Dikshit R, et al. Cancer incidence and mortality worldwide: Sources, methods and major patterns in GLOBOCAN 2012. Int J Cancer 2015;136:E359-86.

4. Campana JP, Meyers AD. The Surgical Management of Oral Cancer. Otolaryngol Clin North Am 2006;39:331-48.

5. Silverman S. Demographics and occurrence of oral and pharyngeal cancers. J Am Dent Assoc 2001;132:7S-11S.

6. Freudlsperger C, Rohleder SE, Reinert S, et al. Predictive value of high $\mathrm{Ki}-67$ expression in stage I oral squamous cell carcinoma specimens after primary surgery. Head Neck 2011;33:668-72.

7. Oliveira LR, Ribeiro-Silva A. Prognostic significance of immunohistochemical biomarkers in oral squamous cell carcinoma. Int J Oral Maxillofac Surg 2011;40:298-307.

8. Watanabe S, Watanabe R, Oton-Leite AF, et al. Analysis of cell proliferation and pattern of invasion in oral squamous cell carcinoma. J Oral Sci 2010;52:417-24.

9. Acay RR, Felizzola CR, Soares de Araújo N, et al. Evaluation of proliferative potential in oral lichen planus and oral lichenoid lesions using immunohistochemical expression of p53 and Ki67. Oral Oncol 2006;42:475-80.

10. Bhuyan L, Sarangi S, Das BK, et al. Proliferative Index in Invasive Tumor Front of Oral Squamous Cell Carcinoma: A Potential Prognostic Indicator. J Contemp Dent Pract 2018;19:170-6.

11. Rangaswami H, Bulbule A, Kundu GC. Osteopontin: role in cell signaling and cancer progression. Trends Cell Biol 2006;16:79-87.

12. Rittling SR, Chambers AF. Role of osteopontin in tumour progression. Br J Cancer 2004;90:1877-81.

13. Bache M, Kappler M, Wichmann H, et al. Elevated tumor and serum levels of the hypoxia-associated protein osteopontin are associated with prognosis for soft tissue sarcoma patients. BMC Cancer 2010;10:132.

14. Petrik D, Lavori PW, Cao H, et al. Plasma Osteopontin Is an Independent Prognostic Marker for Head and Neck Cancers. J Clin Oncol 2006;24:5291-7.

15. Le QT, Sutphin PD, Raychaudhuri S, et al. Identification of osteopontin as a prognostic plasma marker for head and neck squamous cell carcinomas. Clin Cancer Res 2003;9:59-67.

16. Weber GF. The metastasis gene osteopontin: a candidate target for cancer therapy. Biochim Biophys Acta 2001;1552:61-85. 
17. Devoll RE, Li W, Woods KV, et al. Osteopontin (OPN) distribution in premalignant and malignant lesions of oral epithelium and expression in cell lines derived from squamous cell carcinoma of the oral cavity. J Oral Pathol Med 1999;28:97-101.

18. Chien CY, Su CY, Chuang HC, et al. Clinical significance of osteopontin expression in T1 and T2 tongue cancers. Head Neck 2008;30:776-81.

19. Matsuzaki H, Shima K, Muramatsu T, et al. Osteopontin as biomarker in early invasion by squamous cell carcinoma in tongue. J Oral Pathol Med 2007;36:30-4.

20. Jiang L, Zhao LY, He J, et al. The expression and significance of osteopontin and its receptor CD44v6 in oral squamous carcinoma. Hua Xi Kou Qiang Yi Xue Za Zhi 2008;26:248-51.

21. Ingale Y, Routray S, Kheur SM, et al. Evaluating the efficacy of osteopontin expression as a prognostic marker in oral squamous cell carcinoma in the Indian subpopulation. J Oral Maxillofac Pathol 2014;18:S11-5.

22. Lu XZ, Yin XM, Feng YY, et al. Expression of osteopontin mRNA in oral squamous cell carcinoma and normal oral mucosa. Nan Fang Yi Ke Da Xue Xue Bao 2008;28:1165-7.

23. Neville BW, Damm DD, Allen CM, et al. Oral and maxillofacial pathology. Fourth Edition. WB Saunders Company, 2016.

24. Sharifian MJ, Khalili M. Odontogenic cysts: a retrospective study of 1227 cases in an Iranian population from 1987 to 2007. J Oral Sci 2011;53:361-7.

25. Scheer M, Koch AM, Drebber U, et al. Primary intraosseous carcinoma of the jaws arising from an odontogenic cyst - a case report. J Craniomaxillofac Surg 2004;32:166-9.

26. Jain M, Mittal S, Gupta DK. Primary Intraosseous Squamous Cell Carcinoma Arising in Odontogenic Cysts: An Insight in Pathogenesis. J Oral Maxillofac Surg 2013;71:e7-14.

27. Swinson BD, Jerjes W, Thomas GJ. Squamous Cell Carcinoma Arising in a Residual Odontogenic Cyst: Case Report. J Oral Maxillofac Surg 2005;63:1231-3.

28. Borrás-Ferreres J, Sánchez-Torres A, Gay-Escoda C. Malignant changes developing from odontogenic cysts: A systematic review. J Clin Exp Dent 2016;8:e622-8.

29. van der Wal KG, de Visscher JG, Eggink HF. Squamous cell carcinoma arising in a residual cyst. A case report. Int J Oral Maxillofac Surg 1993;22:350-2.

30. Salehinejad J, Saghafi S, Sharifi N, et al. Evaluation of osteopontin and CD44v6 expression in odontogenic cystic lesions by immunohistochemistry. Pathol Res Pract
2012;208:410-4.

31. Routray S, Kheur SM, Kheur M. Osteopontin: a marker for invasive oral squamous cell carcinoma but not for potentially malignant epithelial dysplasias. Ann Diagn Pathol 2013;17:421-4.

32. Aravind T, Janardhanan M, Rakesh S, et al. Immunolocalization of osteopontin in dysplasias and squamous cell carcinomas arising from oral epithelium. J Oral Maxillofac Pathol 2017;21:18.

33. Wang YP, Liu BY. High Expression of Osteopontin and CD44v6 in Odontogenic Keratocysts. J Formos Med Assoc 2009;108:286-92.

34. Gonzalez-Moles MA, Ruiz-Avila I, Gil-Montoya JA, et al. Analysis of Ki-67 expression in oral squamous cell carcinoma: Why $\mathrm{Ki}-67$ is not a prognostic indicator. Oral Oncol 2010;46:525-30.

35. Martin B, Paesmans M, Mascaux C, et al. Ki-67 expression and patients survival in lung cancer: systematic review of the literature with meta-analysis. Br J Cancer 2004;91:2018-25.

36. Petrelli F, Viale G, Cabiddu M, et al. Prognostic value of different cut-off levels of $\mathrm{Ki}-67$ in breast cancer: a systematic review and meta-analysis of 64,196 patients. Breast Cancer Res Treat 2015;153:477-91.

37. Verma R, Gupta V, Singh J, et al. Significance of p53 and ki-67 expression in prostate cancer. Urol Ann 2015;7:488.

38. Kurokawa H, Zhang M, Matsumoto S, et al. The relationship of the histologic grade at the deep invasive front and the expression of $\mathrm{Ki}-67$ antigen and $\mathrm{p} 53$ protein in oral squamous cell carcinoma. J Oral Pathol Med 2005;34:602-7.

39. Tumuluri V, Thomas GA, Fraser IS. Analysis of the $\mathrm{Ki}-67$ antigen at the invasive tumour front of human oral squamous cell carcinoma. J Oral Pathol Med 2002;31:598-604.

40. Lopes VKM, Jesus AS, de Souza LL, et al. Ki-67 protein predicts survival in oral squamous carcinoma cells: an immunohistochemical study. Braz Oral Res 2017;31:e66.

41. Stoll C, Baretton G, Ahrens C, et al. Prognostic significance of apoptosis and associated factors in oral squamous cell carcinoma. Virchows Arch 2000;436:102-8.

42. Cortegoso AVB, Laureano NK, Silva ADD, et al. Cell proliferation markers at the invasive tumor front of oral squamous cell carcinoma: comparative analysis in relation to clinicopathological parameters of patients. J Appl Oral Sci 2017;25:318-23.

43. Klimowicz AC, Bose P, Nakoneshny SC, et al. Basal Ki67 expression measured by digital image analysis is optimal 
for prognostication in oral squamous cell carcinoma. Eur J Cancer 2012;48:2166-74.

44. da Silva SD, Morand GB, Alobaid FA, et al. Epithelialmesenchymal transition (EMT) markers have prognostic impact in multiple primary oral squamous cell carcinoma. Clin Exp Metastasis 2015;32:55-63.

45. Myoung H, Kim MJ, Lee JH, et al. Correlation of proliferative markers (Ki-67 and PCNA) with survival and lymph node metastasis in oral squamous cell carcinoma: a clinical and histopathological analysis of 113 patients. Int J Oral Maxillofac Surg 2006;35:1005-10.

46. Xie S, Liu Y, Qiao X, et al. What is the Prognostic Significance of Ki-67 Positivity in Oral Squamous Cell Carcinoma? J Cancer 2016;7:758-67.

47. Guimarães EP, de Carli ML, Sperandio FF, et al. Cyclin

Cite this article as: Woźniak M, Nahajowski M, Hnitecka S, Rutkowska M, Marek G, Agrawal A, Makuch S, Agrawal S, Ziółkowski P. A comparative study of osteopontin expression, Ki67 index and prognosis in squamous cell carcinoma and cysts of the oral cavity. Transl Cancer Res 2020;9(2):795-808. doi: 10.21037/tcr.2019.12.08
D1 and Ki-67 expression correlates to tumor staging in tongue squamous cell carcinoma. Med Oral Patol Oral Cir Bucal 2015;20:e657-63.

48. Dragomir LP, Simionescu C, Mărgăritescu C, et al. P53, p16 and Ki67 immunoexpression in oral squamous carcinomas. Rom J Morphol Embryol 2012;53:89-93.

49. Motta RR, Zettler CG, Cambruzzi E, et al. Ki-67 and p53 correlation prognostic value in squamous cell carcinomas of the oral cavity and tongue. Braz J Otorhinolaryngol 2009;75:544-9.

50. Coutinho-Camillo CM, Lourenço SV, Nishimoto IN, et al. Nucleophosmin, p53, and Ki-67 expression patterns on an oral squamous cell carcinoma tissue microarray. Hum Pathol 2010;41:1079-86. 